\title{
DEGRADATION STUDY OF ENGINE POLYMERIC COMPONENTS USING SOYBEAN BIODIESEL
}

\author{
SILVEIRA K.P. ${ }^{1}$ \\ ORNAGHI Jr H.L. ${ }^{1}$ \\ WANDER P.R. ${ }^{2}$ \\ CARVALHO G.A. ${ }^{1}$ \\ GIOVANELA M. ${ }^{1}$ \\ RECKZEGIEL K.R. ${ }^{1}$ \\ CRESPO J.S. ${ }^{1, *}$
}

\author{
${ }^{1}$ Centro de Ciências Exatas e da Tecnologia \\ Universidade de Caxias do Sul \\ 95070-560, Caxias do Sul, RS, Brazil \\ ${ }^{2}$ Centro de Ciências Exatas e Tecnológicas \\ Universidade do Vale do Rio dos Sinos \\ 93022-000, São Leopoldo, RS, Brazil
}

Received: 25/01/2015

Accepted: 02/04/2015

*to whom all correspondence should be addressed:

Available online: 25/06/2015 e-mail: jscrespo@ucs.br

\section{ABSTRACT}

An engine industry from Caxias do Sul city (RS, Brazil) has developed tests with biofuels to adapt their products to new fuel trends. Thus, this study aims to examine the components of their engines with potential degradation in the biodiesel usage. The most important aspects that were studied include fuel hoses, sealing rings and painting degradation. This work evaluated polymeric materials in terms of the direct contact with biodiesel from soybean in different proposed compositions with diesel fuel and compared the currently used materials with other elastomers that were proposed by the manufacturers of these components to choose the best performance for this application. The paint performance was also verified to evaluate the resistance aspects to fuels and to compare them to the proposed improvements to these engines. The results indicate that it is possible to use the proposed fuel hoses and sealing rings for some applications in specific biodiesel ratios. Additionally, the blistering and adhesion tests appear to be satisfactory for some of the studied systems.

Keywords: Soybean biodiesel, degradation, polymeric components, biofuel

\section{Introduction}

A major part of the main sources of energy comes from fossils fuels such as petroleum, coal and natural gas (Wiggers et al., 2009). In this sense, there is increasing interest in the use of hydrocarbon fuels derived from renewable resources. This is being driven by the variety of environmental, political and economic concerns and attracting considerable industrial investment for the production of renewable supplies to replace both gasoline and diesel fuel (Flitney, 2007).

Because of its massive territorial extension, excellent climatic conditions (tropical region), high luminosity rates and medium annual temperature, Brazil is considered to be a resource-rich country for exploring the biomass for energetic purposes. Studies performed by the National Biodiesel Board (an organization that addresses the implementation of biodiesel in the United States of America) in 2006 categorically affirm that Brazil has the conditions to lead the world's production of biodiesel and promote the substitution of at least $60 \%$ of the world's current mineral diesel fuel demand (Freitas and Penteado, 2006). The website worldoil.com (http://www.worldoil.com) claims that Brazil has an estimated 
production capacity of 6.2 million tons. In the USA, the biodiesel production industry crossed the billiongallon production for the first time in 2011. The result was repeated in 2012 with more than 1.1 billion gallons produced, and a new record was set in 2013 with 1.8 billion gallons produced (http://biodiesel.org).

Data reported by Centro Técnico Aeroespacial (CTA, Brazil), Instituto de Pesquisas Tecnológicas do Estado de São Paulo (IPT, Brazil) and Centro de Pesquisas da Petrobrás (CENPES, Brazil) indicate that mixtures of diesel fuel with up to $30 \%$ vegetal oil or its methyl/ethyl esters and ternary mixtures of diesel fuel with up to $20 \%$ vegetal oil and $7 \%$ anhydrous ethanol have physical-chemical characteristics and performance in engines that are close to the respective diesel fuel (Araújo, 2002).

Material compatibility is a major concern whenever the fuel composition is changed in the fuel system. Changes in fuel composition and the introduction of alternative fuels often create many problems in seals, gaskets, and o-rings in the fuel systems (Trakarnpuk and Portangitlikit, 2008). In this context, an engine industry from Caxias do Sul city (RS, Brazil) is developing a test that uses biofuels to adapt their products to new market trends. The first results clearly show the necessity of a better evaluation of the polymeric components of these engines with a degradation potential in using biodiesel.

Flitney (2007) was the first researcher to report the performance of fluoroelastomers with various fluorine contents in butan-1-ol and biodiesel fuel mixtures. In another study, Trakarnpuk and Portangjitlikit (2008) investigated the effect of a biodiesel $10 \%$ /diesel fuel $90 \%$ mixture on the properties of some elastomers that are commonly used in automotive applications. In the study of Al-Lal and co-workers (2014), the compatibility of biokerosene blends of coconut, babassu and palm kernel with commercial Jet A-1 testing airplane polymeric materials, metals and composites were investigated.

In view of all these facts, the presented study evaluated the elastomeric polymer components (fuel hose and sealing rings) of an engine (model M90 of Agrale) in direct contact with the diesel fuel, soybean biodiesel, and three biodiesel/diesel mixtures (B5, B25 and B50, where 5, 25 and 50 are the biodiesel contents in $\% \mathrm{v} / \mathrm{v}$, respectively). The results were then compared to the commercial elastomer components that were used by the manufacturer to select the one with better performance/cost ratio. In addition, the behavior of the paints for the painting process of the engines was equally compared to other formulations to propose improvements in this segment.

\section{Experimental}

\subsection{Materials}

The experiments were divided into three parts: swelling of the fuel hose, swelling and tensile tests of the sealing rings, and blistering size/frequency and adhesion of the painting engine parts.

The materials used in this study were: soybean biodiesel (Ipiranga, Brazil, medium fatty acid profile: saturated $\mathrm{C}_{14} 2 \%$ wt., $\mathrm{C}_{16} 8 \%$ wt. and $\mathrm{C}_{18} 3 \%$ wt.; unsaturated $\mathrm{C}_{18: 1} 25 \%$ wt., $\mathrm{C}_{18: 2} 54 \%$ wt. and $\mathrm{C}_{18: 3} 8 \%$ wt.), diesel fuel (Rubilene 813 - Ipiranga, Brazil, complex mixture of hydrocarbons containing primarily normal and branched paraffins, cycloparaffins, and mono- and polyaromatic compounds), lubricant oil (SAE 15W40 - Ipiranga, Brazil), fuel hose (S.A. Mourão, Brazil: NBR/EPDM blend is currently used, NBR was proposed in this study) and sealing ring (Rojel Indústria de Borrachas, Brazil: silicon is currently used, EPDM and NBR/PVC were proposed in this study).

The physico-chemical properties of the soybean biodiesel and diesel fuel are summarized in Table 1 . The paints for the systems were supplied by Sumare Pinturas (Brazil) and divided into three systems as described in Table 2.

\subsection{Preparation of the fuels}

The fuels evaluated in this study have the following composition: (i) $100 \%$ diesel fuel [B0]; (ii) $5 \%$ biodiesel and $95 \%$ diesel fuel [B5]; (iii) $25 \%$ biodiesel and 75\% diesel fuel [B25]; (iv) 50\% biodiesel and 50\% diesel fuel [B50]; (v) 100\% biodiesel [B100]. 
Consequently, five mixtures of lubricant oil SAE $15 \mathrm{~W}-40$ were prepared, which contained $10 \%$ of each cited fuel in such a manner to simulate the contamination of this oil that remains in close contact with the seal rings of the tested engines.

Table 1. Physico-chemical properties of soybean biodiesel and diesel fuel.

\begin{tabular}{lccc}
\hline Property & Method & $\begin{array}{c}\text { Soybean } \\
\text { biodiesel }\end{array}$ & $\begin{array}{c}\text { Diesel } \\
\text { fuel }\end{array}$ \\
\hline Density $\left(\mathrm{kg} \mathrm{m}^{-3}\right)$ at $20^{\circ} \mathrm{C}$ & ASTM D1298 & 884 & 854 \\
\hline Flash point $\left({ }^{\circ} \mathrm{C}\right)$ & ASTM D93 & 174 & 75 \\
\hline Cold filter plugging point $\left({ }^{\circ} \mathrm{C}\right)$ & ASTM D6371 & -5.0 & -12 \\
\hline Kinematic viscosity $\left(\mathrm{mm}^{2} \mathrm{~s}^{-1}\right)$ at $40{ }^{\circ} \mathrm{C}$ & ASTM D445 & 4.32 & 5.0 \\
\hline lodine index $(\mathrm{g} / 100 \mathrm{~g})$ & EN 14111 & 140 & - \\
\hline Sulfur content $\left(\mathrm{mg} \mathrm{kg}^{-1}\right)$ & ASTM D1552 & 1.8 & 750 \\
\hline Total acid number $\left(\mathrm{mg} \mathrm{KOH} \mathrm{g}^{-1}\right)$ & ASTM D664 & 0.29 & - \\
\hline Oxidation stability at $110^{\circ} \mathrm{C}(\mathrm{h})$ & EN 14112 & 4.93 & - \\
\hline Ash content (wt $\%)$ & ASTM D874 & 0.006 & - \\
\hline Cetane index (minimum) & ASTM D976 & - & 42 \\
\hline
\end{tabular}

Table 2. Description of the paints used.

\begin{tabular}{ccccc}
\hline System & Color & Primer & Paint based & Application \\
\hline 1 & Gray & Alkyd $-\mathrm{ZnCrO}_{4}$ & Polyurethane & Engine \\
\hline 2 & Black & Alkyd $-\mathrm{ZnCrO}_{4}$ & Alkydic & Chassis \\
\hline 3 & Red & Vinilic & Polyurethane & Engine \\
\hline
\end{tabular}

\subsection{Preparation of the painted panels}

Initially, the steel panels $(100 \times 150 \times 1 \mathrm{~mm})$ were degreased and phosphatized. Then, the panels were painted in the spray booth using conventional gun pressures. Each system had applications of primers and finishing paints on the thickness that were recommended by the paint manufacturer.

Table 3. Blister size description, frequency blister description and percent area removed, which was classified according to ASTMD3359-02 and ASTM D714-02.

\begin{tabular}{cccccc}
\hline Category & $\begin{array}{c}\text { Blister size } \\
\text { description }^{(a)}\end{array}$ & Category & $\begin{array}{c}\text { Frequency blister } \\
\text { description }^{(\text {a) }}\end{array}$ & Classification & $\begin{array}{c}\text { Percent area } \\
\text { removed }^{(\mathbf{b})}\end{array}$ \\
\hline 2 & Blister size $>2 \mathrm{~mm}$ & None (N) & No area affected & $1 \mathrm{~A}$ & 0 \\
\hline 4 & $\begin{array}{c}1 \mathrm{~mm}<\text { blister size } \leq \\
2 \mathrm{~mm}\end{array}$ & Few (F) & Area affected $\leq 1 / 5$ & $2 \mathrm{~A}$ & 15 \\
\hline 6 & $\begin{array}{c}0.5 \mathrm{~mm}<\mathrm{blister} \mathrm{size} \\
\leq 1 \mathrm{~mm}\end{array}$ & Medium (M) & $\begin{array}{c}1 / 5<\text { area affected } \leq \\
1 / 4\end{array}$ & $3 \mathrm{~A}$ & 35 \\
\hline 8 & Blister size $\leq 0.5 \mathrm{~mm}$ & $\begin{array}{c}\text { Medium } \\
\text { Dense (MD) }\end{array}$ & $\begin{array}{c}1 / 4<\text { area affected } \leq \\
1 / 2\end{array}$ & $4 \mathrm{~A}$ & 65 \\
\hline 10 & No blistering & Dense (D) & Area affected $>1 / 2$ & $5 \mathrm{~A}$ & 100 \\
\hline
\end{tabular}

${ }^{(a)}$ ASTM D714-02, ${ }^{(b)}$ ASTM D3359-02

The painted panels were immersed in the fuels for $72 \mathrm{~h}$ in total with an extraction of one panel of each system every $24 \mathrm{~h}$. When the test was completed, the specimens were cleaned and dried, and a waiting period of $24 \mathrm{~h}$ (regeneration film period) occurred to promote the evaluation degree of blistering of the paints according to ASTM D714-02 and the adhesion using test tape according to ASTM D 3359-02 (Table 3). 


\subsection{Swelling of the hose and sealing ring}

The hose fuel samples were cut into $2 \mathrm{~mm}$ sections, weighed and submitted to the swelling test in the fuels for $18 \mathrm{~h}$ at a temperature of $22 \pm 2{ }^{\circ} \mathrm{C}$ according to an adaptation of ASTM D3616/95. The seal rings were submitted to lubricant oil (SAE 15W-40 - Ipiranga, Brazil) contaminated with $10 \%$ (v/v) of each fuel.

When the test was completed, the solvent excess was removed and the samples were weighed again. The swelling index (SI) was determined as follows (Eq. 1):

$\mathrm{SI}=\mathrm{m}_{\text {swelled }} / \mathrm{m}_{\text {initial }}$

where $m_{\text {swelled }}$ is the mass of the swelled sample, and $m_{\text {initial }}$ is the initial mass sample.

\subsection{Tensile tests}

The seal rings were conditioned to a temperature of $23 \pm 2{ }^{\circ} \mathrm{C}$ and relative humidity of $55 \%$ for the tensile tests according to ASTM D 412/98a. For each sample, five valid specimens were used.

\section{Results and discussion}

\subsection{Swelling of the fuel hoses}

The fuel hoses show a swelling for all studied fuel samples (Figure 1). The proposed NBR hose shows a small increase in swelling with biodiesel incorporation, where the current NBR/EPDM hose shows higher swelling.

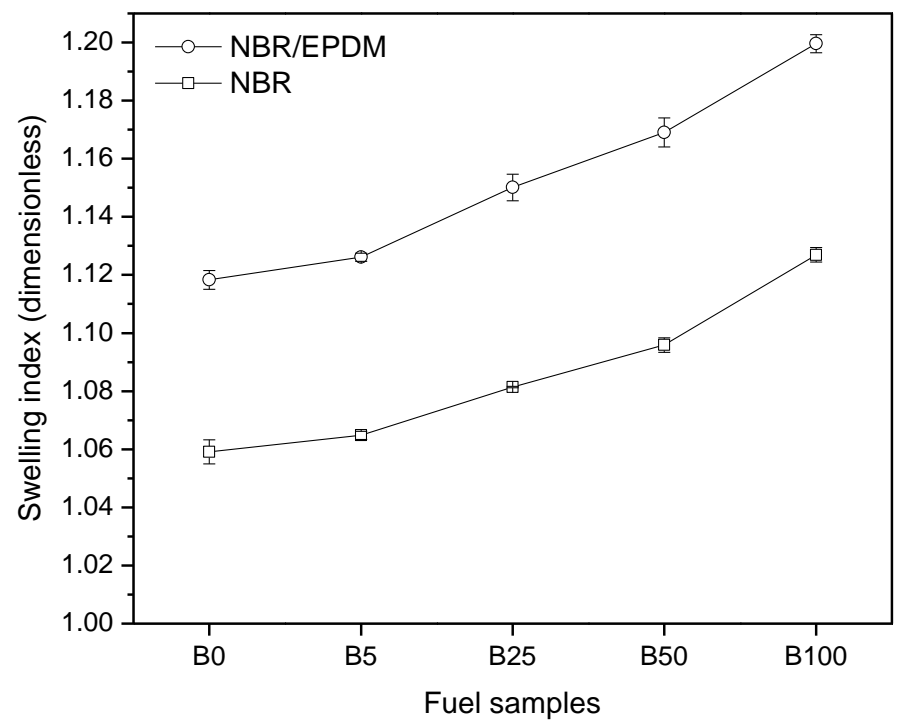

Figure 1. Swelling index of the NBR/EPDM and NBR fuel hoses immersed in the fuel samples. The lines are drawn as a guide to the eyes

Because of its apolar character, the studied fuels has higher affinity with the apolar EPDM structure (Usuki et al., 2002), which results in a higher swelling index for the hose NBR/EPDM. However, both samples showed an increase in swelling index with biodiesel incorporation due to the interaction of esters groups with the nitrile group of NBR. Hence, the proposed NBR hose appears to be more adequate and can be used in all proposed biodiesel compositions. These results imply a reduction of approximately $35 \%$ of the cost compared to the current NBR/EPDM fuel hose. The obtained results can be explained using the chemical affinity of the elastomer molecules with the studied fuels. 


\subsection{Characterization of the sealing rings}

\subsubsection{Swelling index}

Independently of the biodiesel composition, the sealing rings show similar swelling index values. The difference among the three tested materials is shown in Figure 2. The NBR/PVC sample shows a small swelling degree because of its polar character (George et al., 2003). Again, because of the chemical affinity with the studied fuels, EPDM shows the highest swelling degree. According to Al-Lal et al. (2014), the elastomers allow the inclusion of fuel molecules between the polymeric chains. Such inclusion is not observed in thermoplastics, such as PVC. Conversely, the silicon samples have intermediate swelling indices. The proposed NBR/PVC seal ring shows the highest performance, and based on this study, its usage implies a reduction of approximately $30 \%$ of the cost relative to the current silicon seal ring.

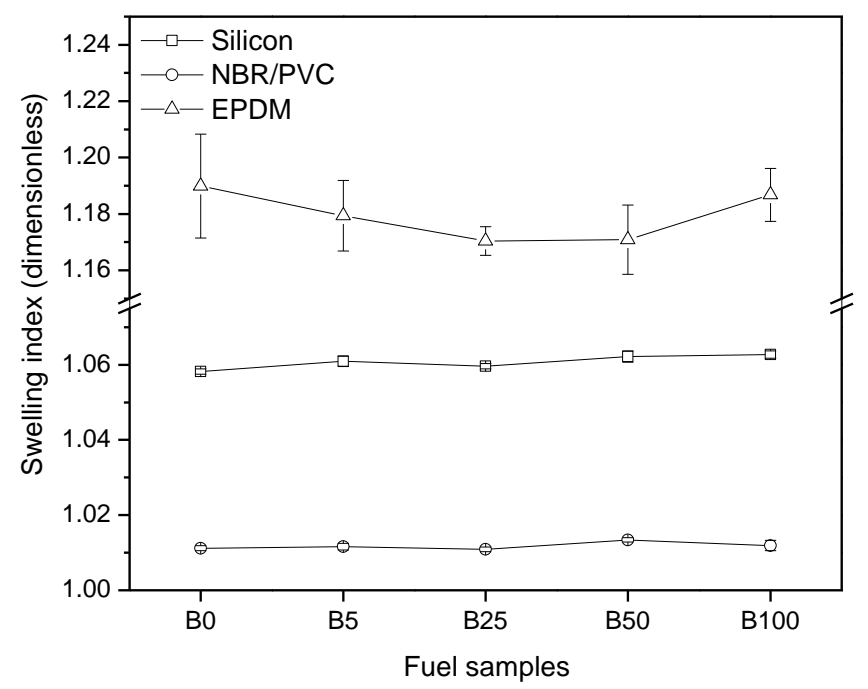

Figure 2. Swelling index of the sealing rings immersed in the fuel samples. The lines are drawn as a guide to the eyes.

\subsubsection{Tensile tests}

From the tensile tests, some mechanical properties of the samples that were submitted to the swelling test were evaluated and compared to the virgin sample. Figure 3 shows the results of the elongation at break, tensile strength and modulus at $300 \%$. The modulus at $300 \%$ is defined as the tensile stress necessary to elongate a specimen to $300 \%$ of its original length. Although other elongations may be used (as $50 \%$ and $100 \%$ ), $300 \%$ is the one most often employed for rubber and flexible polymers (Gujel et al., 2014). In general, the evaluated mechanical properties of the silicon samples remain unaffected after the swelling test because these samples have small swelling indices. However, for the EPDM samples, all properties decrease after the immersion compared to the virgin sample. The inclusion of fuel molecules between the elastomeric chains lowering the mechanical properties. For the NBR/PVC sample, the chlorine presence in PVC enhances the tensile strength and modulus ate $300 \%$ after the fuel immersion (Al-Lal et al., 2014).

As observed for the fuel hose, the results obtained for the seal ring can be explained based on the polarity of the molecules of the tested materials. Both diesel fuel and biodiesel are predominantly apolar and they therefore interact more with EPDM, whereas silicon elastomer (medium polarity) and NBR/PVC (high polarity) are less chemically attacked by these fuels. This fact justifies the mechanical properties that were obtained for the seal rings before and after the swelling test. 


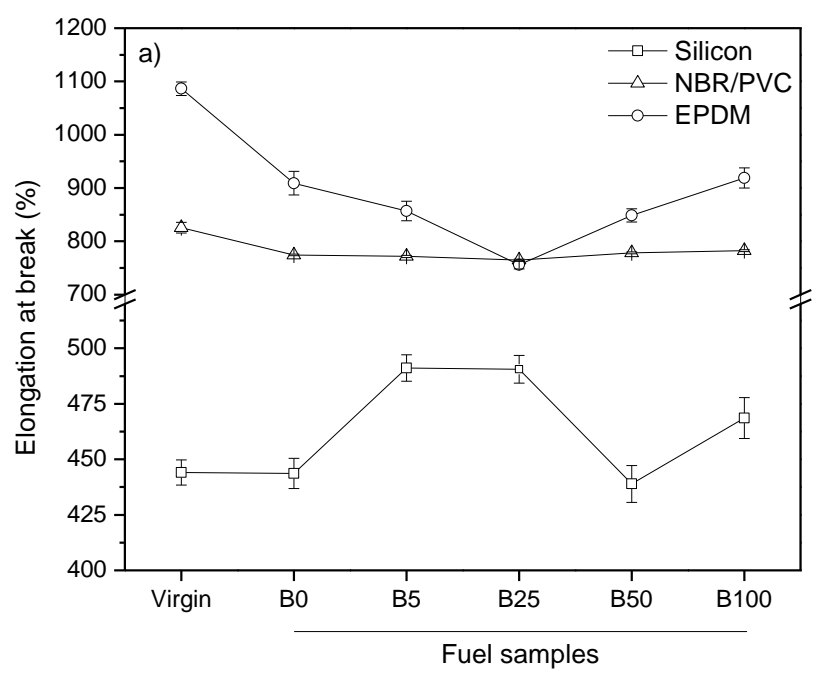

(a)

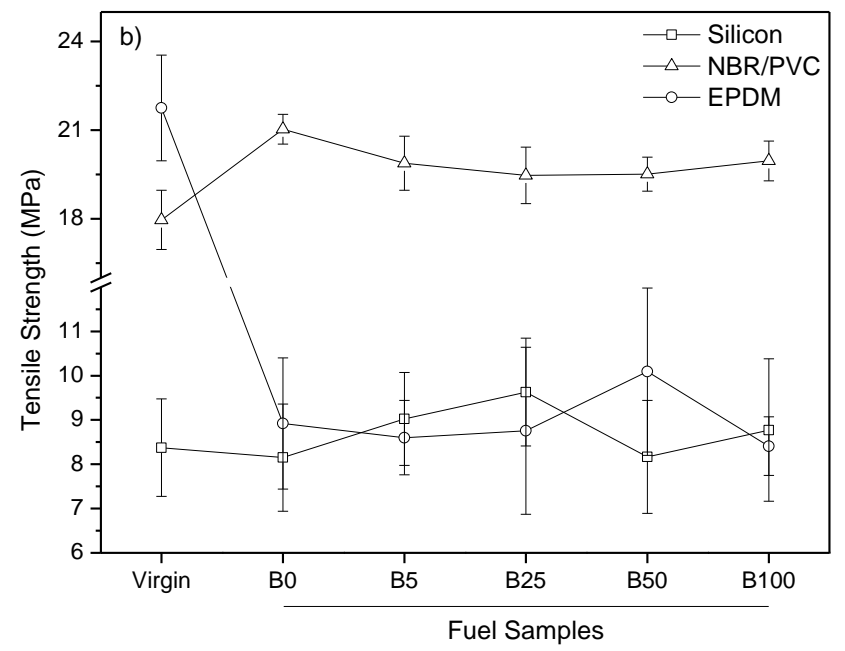

(b)

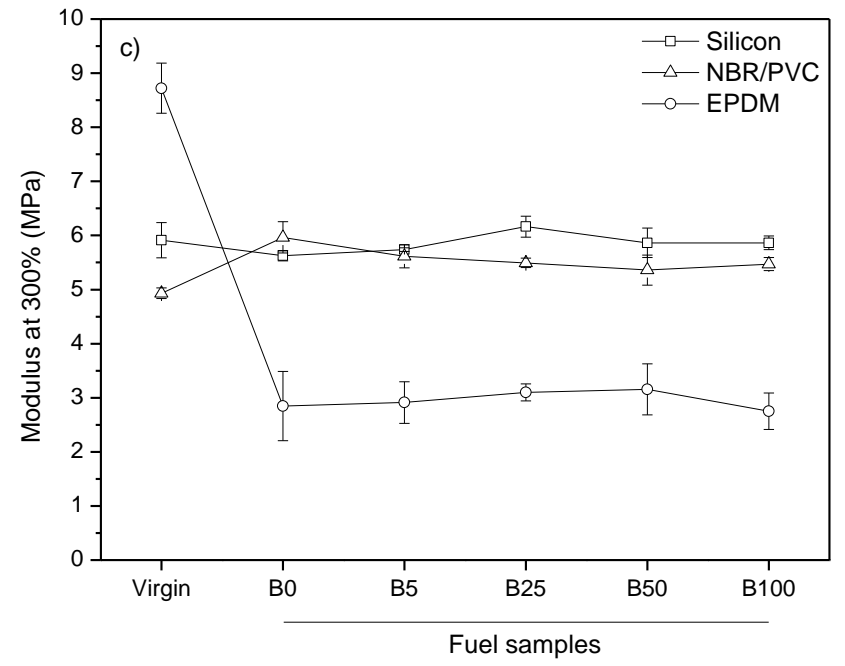

(c)

Figure 3. (a) Elongation at break, (b) tensile strength and (c) tensile modulus at $300 \%$ for the virgin sealing rings and after immersion in the fuel samples. The lines are drawn as a guide to the eyes. 


\subsection{Evaluation of the paints}

Because biodiesel is constituted by a mixture of carboxylic acid esters, it solubilizes a higher group of organic substances, including those of the paints. Thus, special care must be taken with the biodiesel handle to avoid damage to the vehicle paint near both the point and the supply nozzle. In addition to the solvent power of the biodiesel, the polarity of the molecules of these fuels interferes with the resistance for each ink.

Resin-based alkydic (Systems 1 and 2) and resin-based vinyl (System 3) have apolar structures and are easily attacked by diesel fuel and biodiesel. The resin-based polyurethane (System 1 and 3 ) is not affected by the contact with the fuels because of its polar nature. The blistering visual test and adhesion test for systems 1, 2 and 3 are visualized in Figures 4 and 5, respectively. The category/classification of the systems (Table 4) was based on Table 3.

Table 4. Results of the blistering size, frequency and adhesion tests.

\begin{tabular}{|c|c|c|c|c|}
\hline \multirow{2}{*}{ Paint } & \multirow{2}{*}{ Fuel } & \multicolumn{3}{|c|}{ Results of blistering size/frequency/adhesion ${ }^{(a)}$} \\
\hline & & $24 h^{(b)}$ & $48 h^{(b)}$ & $72 h^{(b)}$ \\
\hline \multirow{5}{*}{ System 1} & B0 & $10 / N / 1 A$ & $8 / F / 1 A$ & $8 / F / 1 A$ \\
\hline & B5 & $8 / F / 2 A$ & $8 / F / 2 A$ & $8 / F / 2 A$ \\
\hline & $\mathrm{B} 25$ & $8 / F / 2 A$ & $8 / F / 2 A$ & $8 / F / 3 A$ \\
\hline & $\mathrm{B} 50$ & $8 / F / 3 A$ & $6 / \mathrm{M} / 4 \mathrm{~A}$ & $6 / \mathrm{M} / 4 \mathrm{~A}$ \\
\hline & B100 & $8 / \mathrm{M} / 5 \mathrm{~A}$ & $6 / \mathrm{M} / 5 \mathrm{~A}$ & $6 / \mathrm{M} / 5 \mathrm{~A}$ \\
\hline \multirow{5}{*}{ System 2} & $\mathrm{BO}$ & $10 / \mathrm{N} / 2 \mathrm{~A}$ & $10 / N / 3 A$ & $10 / N / 3 A$ \\
\hline & B5 & $10 / \mathrm{N} / 2 \mathrm{~A}$ & $10 / N / 3 A$ & $10 / N / 3 A$ \\
\hline & $\mathrm{B} 25$ & $10 / N / 2 A$ & $10 / N / 3 A$ & $10 / N / 3 A$ \\
\hline & $\mathrm{B} 50$ & $10 / \mathrm{N} / 3 \mathrm{~A}$ & $10 / N / 3 A$ & $10 / N / 3 A$ \\
\hline & B100 & $10 / N / 5 A$ & $6 / \mathrm{M} / 5 \mathrm{~A}$ & $6 / \mathrm{MD} / 5 \mathrm{~A}$ \\
\hline \multirow{5}{*}{ System 3} & $\mathrm{BO}$ & $10 / \mathrm{N} / 0 \mathrm{~A}$ & $10 / \mathrm{N} / 0 \mathrm{~A}$ & $10 / N / 1 \mathrm{~A}$ \\
\hline & B5 & $10 / \mathrm{N} / 0 \mathrm{~A}$ & $10 / N / 1 \mathrm{~A}$ & $10 / N / 1 \mathrm{~A}$ \\
\hline & B25 & $10 / \mathrm{N} / 0 \mathrm{~A}$ & $10 / N / 1 \mathrm{~A}$ & $10 / N / 1 \mathrm{~A}$ \\
\hline & $\mathrm{B} 50$ & $10 / \mathrm{N} / 0 \mathrm{~A}$ & $10 / N / 1 A$ & $10 / N / 1 \mathrm{~A}$ \\
\hline & B100 & $10 / \mathrm{N} / 0 \mathrm{~A}$ & $10 / \mathrm{N} / 1 \mathrm{~A}$ & $10 / N / 1 \mathrm{~A}$ \\
\hline
\end{tabular}

${ }^{(a)}$ According to Table 3; ${ }^{(b)}$ Immersion time of the sample in the fuel.

For system 1, it can be observed a higher removed area with the biodiesel incorporation. Also, the blister size tends to increase. For system 2, by the other hand, the effect of the biodiesel incorporation was less pronounced on both parameters (removed and blister area) with exception of the B100 samples.

Additionally, the removed areas showed a similar trend with exception of the immersed sample for $24 \mathrm{~h}$. Finally, for system 3, no significant differences were found for all samples with different immersion times.

Table 5 shows the comparative results of the blister and adhesion tests based on Table 4. It can be noted that for system 3, for the blistering and adhesion tests, all biodiesel proportions were approved. However, for the adhesion test, no biodiesel ratio was approved for Systems 1 and 2, with the exception of System 1 for B5 oil.

Based on Table 5, it can be concluded that the most adequate alternative for the application of paints in biodiesel usage is the system of the polyurethane based. Because of the compatibility of these resins, it is necessary to use the vinylic primer for the finished paint in polyurethane to ensure their adherence. Considering the cost by liter of the paint, yield liter and width of the layer for each system, the cost is reduced by $44 \%$ when the alkyd primer is used, in comparison to the vinylic primer.

Relative to the paint systems, it can be observed that the polyurethane resin is the most recommended resin for application in paints with biodiesel in any mixture fraction, but it has a higher cost than the alkydic systems. To replace the alkyd primers for vinylic primers and paint based polyurethane gray 
(already used in the industry for other applications), the cost increases by approximately $61 \%$. However, to replace the alkyd primer by based polyurethane paint black (already used for other applications), the cost increases by approximately $88 \%$.

Table 5. Comparative study of the paint systems.

\begin{tabular}{|c|c|c|}
\hline Paint system & Blistering & Adhesion \\
\hline \multirow{5}{*}{ System 1} & $\mathrm{BO}$ & BO \\
\hline & B5 & B5 \\
\hline & B25 & B25 \\
\hline & B50 & B50 \\
\hline & B100 & B100 \\
\hline \multirow{5}{*}{ System 2} & BO & BO \\
\hline & B5 & B5 \\
\hline & B25 & B25 \\
\hline & B50 & B50 \\
\hline & B100 & B100 \\
\hline \multirow{5}{*}{ System 3} & BO & $\mathrm{B} 0$ \\
\hline & B5 & B5 \\
\hline & B25 & B25 \\
\hline & B50 & B50 \\
\hline & B100 & B100 \\
\hline
\end{tabular}

The items in "gray color" represent the systems that were not approved in the tests.

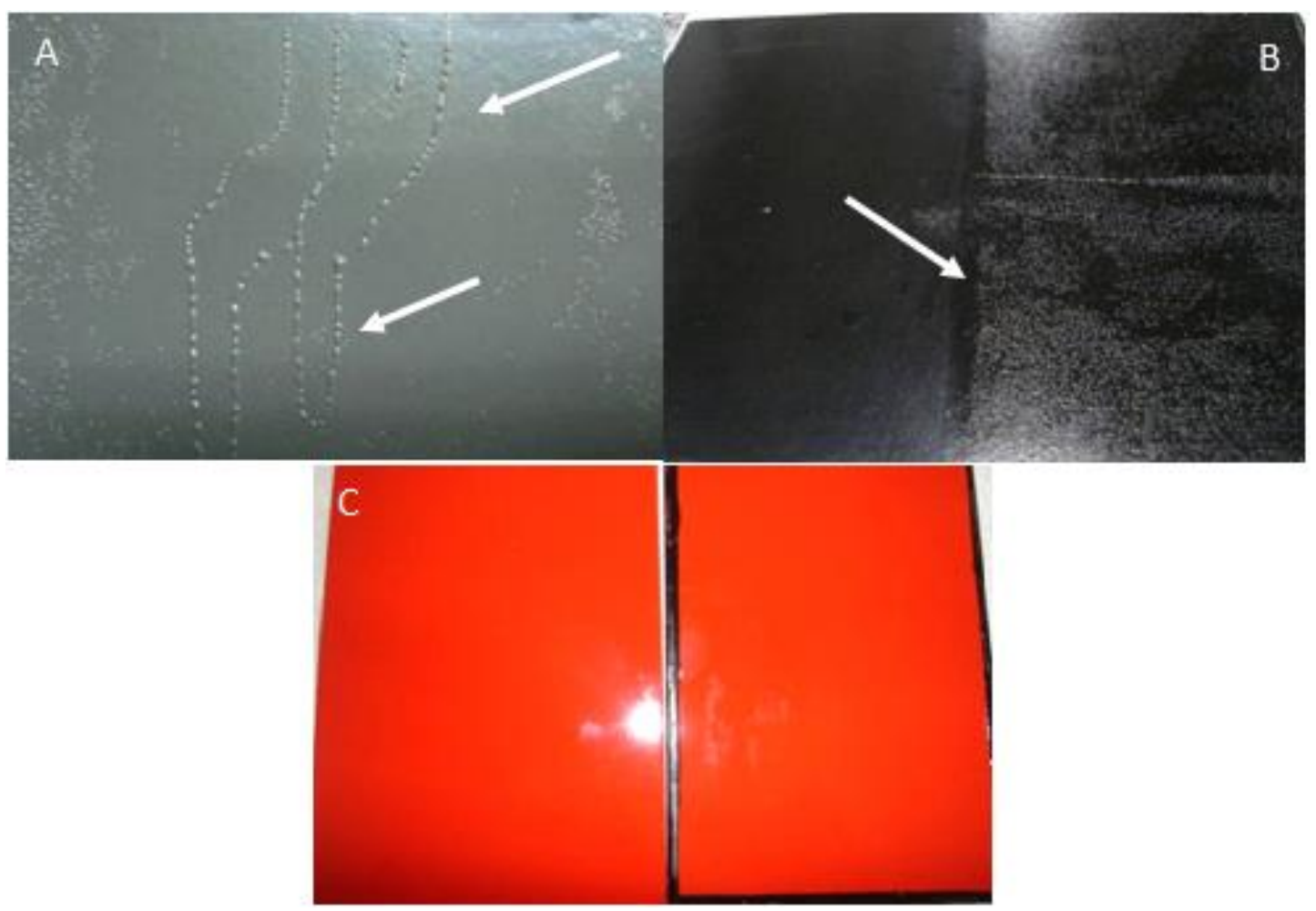

Figure 4. Blistering test for the samples that were immersed $72 \mathrm{~h}$ in B100: (a) System 1, (b) System 2 and (c) System 3. The arrows in Figs. $\mathbf{4 a}$ and $\mathbf{4 b}$ indicate the blister visualization that is not observed in system 3 (Fig. 4c). 

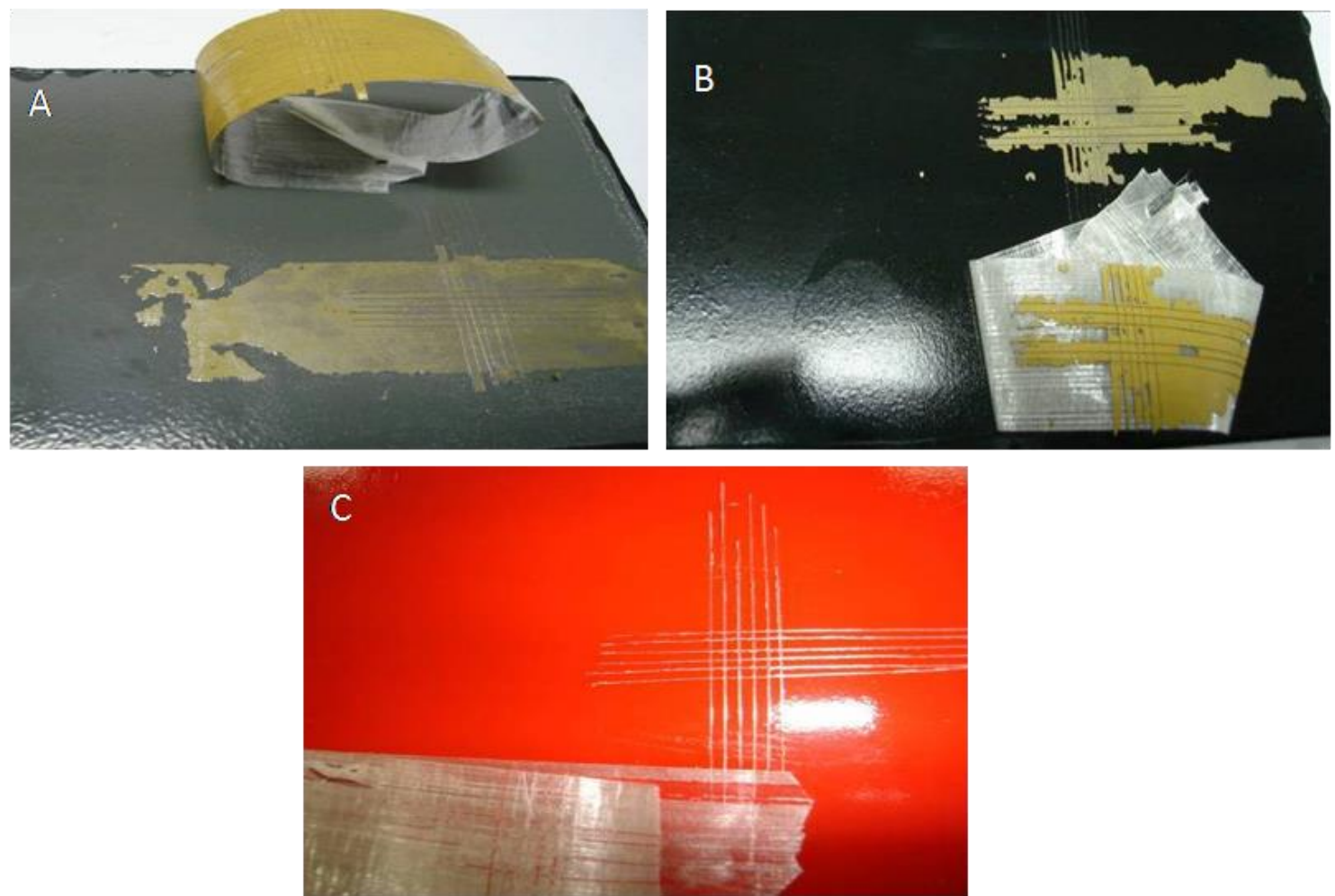

Figure 5. Adhesion test for the samples that were immersed $24 \mathrm{~h}$ in B100: (a) System 1, (b) System 2 and (c) System 3.

\section{Conclusion}

For the application of fuel hoses, it can be concluded that the nitrilic NBR elastomer shows better performance than the NBR/EPDM elastomer with a cost reduction of $35 \%$. The physical mixture NBR/PVC shows better performance in the seal ring test than the silicon and EPDM elastomers, with a cost reduction of approximately $30 \%$. For the paints, satisfactory results were found when the vinylic primer (System 3) was used, i.e., for both blistering and adhesion tests. This study shows that it is possible to evaluate the behavior of some polymeric components of the engine industry with the use of soybean biodiesel and shows satisfactory results for the proposed materials.

\section{Acknowledgements}

The authors would like to thank Agrale for supplying the materials and CAPES/PNPD for the financial support.

\section{References}

Al-Lal A., Llamas A., Bolonio D., Sanz-Pérez F., Lapuerta M. and Canoira L. (2014), Airplane materials compatibility with blends of fossil kerosene jet A1 with biokerosenes from babassu, palm kernel and coconut oils, Global NEST Journal, 16(6), 1066-1075.

Araújo K.M., Oliveira A.K.C., Costa G.B., Queiroga R.N.G and Pannir Selvam P.V. (2002), Estudo comparativo técnico e econômico de diferentes óleos vegetais brasileiros para produção de biocombustível, Proceedings of the 4th Encontro de Energia no Meio Rural, 1-9.

Biodiesel America's Advanced Biofuel (accessed Nov. 2014). http://biodiesel.org

Flitney B. (2007), Which elastomer seal materials are able for use in biofuels? Sealing Technology, 9, 8-11.

Freitas C. and Penteado M. (2006), Biodiesel Energia do Futuro, Letra Boreal, São Paulo.

George K.E., Joseph R. and Francis D.J. (2003), Studies on NBR/PVC blends, Journal of Applied Polymer Science, 32, 2867-2873. 
Gujel A.A., Bandeira M., Giovanela M., Carli L. N., Brandalise R.N. and Crespo J.S. (2014), Development of bus rubber profiles with additives from renewable sources: Part II - Chemical, physical-mechanical and aging characterization of elastomeric compositions, Materials \& Design, 53, 1119-1123.

Oki M. and Nakanishi H. (1970), Conformations of the ester group, Bulletin of the Chemical Society of Japan, 43, 2558-2566.

Trakarnpruk W. and Porntangjitlikit S. (2008), Palm oil biodiesel synthesized with potassium loaded calcined hydrotalcite and effect of biodiesel blend on elastomers properties, Renewable Energy, 33, 1558-1563.

Usuki A., Tukigase A. and Kato M. (2002), Preparation and properties of EPDM-clay hybrids, Polymer, 43, $2185-2189$.

Wiggers V.R., Meier H.F., Wisniewski Jr. A., Chivanga Barros A.A. and Wolf Macel M.R. (2009), Biofuels from continuous fast pyrolysis of soybean oil: A pilot plant study, Bioresource Technology, 100, 6570-6577.

World Oil (accessed Nov. 2014), http://www.worldoil.com 